\title{
Young Adults and Aggression: A Comparative Study of Gender Differences
}

\author{
Nahida Shaban ${ }^{1}$, Dr. Pardeep Kumar ${ }^{2} *$
}

\section{ABSTRACT}

Aggression or anger is an emotion felt by almost all of us in daily life. But in young adult age especially in student's life this emotion can be very harmful if not managed properly. The current study investigates the level and gender differences in aggression by involving 100 participants ( $N=100,50$ Males \& 50 Females) from Lovely Professional University, Punjab. The age of the participants range from 18 to 25 (Mean = 22.44) years. The Aggression Scale has been used over a period of two months to collect data from both the genders. The results of the study present some interesting figures suggesting that female participants experience high aggression (30\%) in comparison to male participants (22\%). The results also suggest that overall 26\% participants experience high aggression indicating that one fourth of the participants are on the higher side of aggression. Further, the results also indicate that though the percentage of female participants is high on aggression, but they do not differ significantly $(\mathrm{t}=-.568, \mathrm{p}>.05$ ) to their male counterparts on aggression. The results also differ from the general notion that males are aggressive than females. The results suggest that currently the pattern of aggression is changing and, in modern times, both males and females experience almost equal aggression.

\section{Keywords: Aggression, Young Adults, Gender Differences}

The term aggression is a used frequently to describe the behavioral activities of others as well as ourselves. In psychology, the concept of aggression is referred to a variety of behavior which results in emotional as well as physical harm to an individual. Social psychologists explain aggression as an action that is planned to harm those people who do not want to be harmed (Baron \& Richardson 1994).

Aggression is also manifested in different ways as physical, verbal, relational, cyber bulling and accidental aggression. Physical aggression mainly include hitting, beating, kicking or use

\footnotetext{
${ }^{1}$ Department of Psychology, Lovely Professional University, Punjab, India

${ }^{2}$ Department of Psychology, Lovely Professional University, Punjab, India

*Responding Author

(C) 2016 I N Shaban, P Kumar; licensee IJIP. This is an Open Access Research distributed under the terms of the Creative Commons Attribution License (http://creativecommons.org/licenses/by/2.0), which permits unrestricted use, distribution, and reproduction in any Medium, provided the original work is properly cited.
} 


\section{Young Adults and Aggression: A Comparative Study of Gender Differences}

weapons etc or causing damage to household or other positions Buss (1961). Most people display highest levels of physical aggression in childhood and this behavior declines with the age with proper care and concentration. Physical aggression also leads to drug addiction, crimes, accidents, suicidal activities, depression, abuse by spouse and neglect parenting. Verbal aggression is thought to be mainly a destructive form of communication with intent to disturb others. Relational Aggression is also known as covert or indirect aggression (Crick \& Grotpeter, 1995) It is a type of aggression in which we intentionally damaging someone's social status or relationship which can occur between different age groups, in family matters, in professional life or among the people of society. It sometimes also refers to hurting someone's reputation or relationship. Cyber bullying is an action of harming or harassing peoples via information technology, electronic devices, mass media or social network in a repeated or deliberated manner. Cyber bullying can be done to a person to incarnate hatred in other mind toward a particular person or a group or it can be used as a tool to surely humiliating some' one with the increased use of technology. Cyber bullying has become common in teenagers. Accidental aggression is a type of aggression in which a person hurts the other individual unintentionally for example unknowingly stepping on another's foot while playing a game putting on the coat sleeves unknowing hitting on someone with our arm. Accidental aggression does not happen purposely but it happens unknowingly.

A wide spectrum of factors has been associated with the development and persistence of aggressive behavior among young adults including males and females. Understanding the relationship among these factors and youth aggression provides important insights for developing prevention interventions. There is little amount of work on aggression among youth in India. Considering this backdrop and research gap, we propose the present study to find out the level and gender difference in aggression among young adults on Indian sample.

\section{REVIEW OF LITERATURE}

Around 1950s, a number of pioneering researches were done on aggression especially focusing on adolescents, young men, adults and women. These studies suggested that males, particularly young male adults, are more aggressive than their female counterparts. But the concept of aggression has changed especially in gender view. The change is set that an increase in the number of criminal act and antisocial acts are committed by young girls. There is statistical proof that gender differences are more sufficient in the stage of adolescence than any other stage (Estevez et al., 2012). Awareness of the gender stereotypes increases during growth and development of the person. During the childhood gender stereotype are stiff but imprecise as, they enter adolescence boys and girls develop the new cognitive skills and they become more aware of the plurality of approaches to gender roles. Adolescents are able to achieve greater objectivity from external perceptions to generate more autonomous, propositional thinking, critical, and to relativism more widely the traits assigned by society to men and women. Eagly and Steffen (1986) indicated that even if men were to some extent more aggressive as compare to 


\section{Young Adults and Aggression: A Comparative Study of Gender Differences}

women on different parameters but gender differences were sufficiently linked to various attributes of the studies. Especially, men were more indulge in those aggressive activities that direct toward injury or pain rather that create social or psychological damage. They further emphasized that in aggression the sex differences are mainly outcome of perceived consequences in aggression which are studied as social aspects as well as roles of gender. Bjorkqvist et al. (1994) compared physical and direct verbal aggression in males and females. The subjects were university employees including (162 males and 172 females) the tool was harassment measuring scale by Bjorkqvist et al. which was given in (1994) and in this tool the more emphasis was given to two subscales named social manipulation and rational appearing aggression. The result revealed that the males were high on physical aggression in comparison to females, whereas females were high on direct verbal aggression from males.

Smritikana Mitra Ghosh (2012) conducted a comparative study on aggression between girls and boys. This study consists of 100 adolescents 50 boys and 50 girls of age 14 to 16 years. The outcome revealed that there was no significant difference between girls and boys on aggression. Barbara Krahe et al. (2005) conducted a study to examine the sex difference in relationship aggression among young adults and this study consisted of 248 women and 400 men between the aged of 17 to 29 years. The results concluded that women scored higher in aggression acts than men.

Kenneth E. Leonard (2002) conducted a study to estimate the prevalence location and severity of aggression in one year among the community and college young adults. Their results indicated that $25 \%$ of women and $33 \%$ of men experienced aggression. Jamal Akhtar et al. (2015) conducted a study to compare the gender difference in aggressive behavior in adolescence. The sample consists of two hundred teenagers of which 100 were boys and 100 were girls. The results revealed that the boys are higher in aggression as compared to girls. Edalati et al. (2010) concluded that according to existing literature the female physical aggression is almost equal to or higher than males but not less than males. Bettencourt and Miller (1996) conducted a study to find out the consequences or effect of provocation in aggression among gender differences. The study reveals that the men who are unprovoked are more aggressive as compare to women. Gender differences in terms of appraisals, the intensity of provocation or threat by retaliation to some extent mediates the reduced effect of provocation but, they do not show the entire details of its manipulated effect. Furthermore, the study revealed that the magnitude and as well as the intensity in aggression of gender differences are also affected by the type of provocation and other variables. Fares et al. (2011) conducted a study on children and adolescents to examine the justification of aggressive acts in various social situations as a function of age, sex, and the effect of differences in socioeconomic status. The data was collected from participants aged 8 to 21 by using self-report questionnaire, to measure the aggressive acts in six social situations. The results indicated that the level of aggression justified by physical and verbal aggression was more in adolescents than children in many situations. The results also showed that boys justified physical 


\section{Young Adults and Aggression: A Comparative Study of Gender Differences}

aggression more easily than girls. Veiskarami et al. (2015) conducted a study among males and females who are victims of physical aggression. Four schools from Iran were selected for the study. The data was collected by using Bullying victimization scale (BVS) and the results indicated that boys average score was higher than girls. Fries et al. (2013) conducted a study Gender segregations in analyzing of Self-Reported Physical violence within Adolescents from Santiago, Chile within a community sample of youngsters (ages groups 11 - 17). The sample consisted of men and women and the results discovered that teenager women reported engaged more in physical hostility than men. The subjects established that higher levels of aggression was reported with-younger age, fewer family participation, fewer parental power, less positive dealings with caregivers, having more friends who act out and use substances, having fewer friends dedicated to learning, company of date cruelty, and more experienced to locality crime. They also concluded that there was need for repercussion for avoidance and involvement efforts to tackle high-risk adolescents and reduce hostility amid Chilean youth. Crick and Grotpeter (1995) conducted a study on Relational Aggression, Social psychological adjustment and Gender. In this study, a form of violence hypothesized to be typical of girls, relational aggression was calculated to the sample of 491 third during sixth-grade children. Physical and verbal violence and social psychological adjustment were also calculated.. Results indicated that the girls were significantly more relationally aggressive than boys. Their findings also showed that relationally violent children may be at risk for severe adjustment difficulties and have much higher levels of depression, loneliness, and isolation than their none relationally destructive peers. Hay (2007) conducted a study on sex differences in aggression. In the observational studies and other studies that are recently conducted, it is revealed that during infancy there is a similar rate among boys and girls of using force. Boys are supposed to become significantly more aggressive over the next few years. Moreover, the evaluation for alternative hypothesis accounting for the widening of gap between the genders has been done which includes the hypothesis about normative patterns of desistence of female and escalation of male; preference given by boys for active play in order to promote aggression tendency of girls to hide their aggression; use of other alternate ways of aggression by girls increased risk among boys that are linked to aggression which may be the risk for cognitive as well as emotional problems; sensitivity of boys towards situational triggers of aggression; and also the vulnerable approach towards the adverse rearing environments. Thus, there are mixed evidences on each hypothesis. Basically, the general differences among the sexes happen to be produced by a less number of boys who show high rate of aggression deployment. Parker et al. (2005) conducted a study on young adolescents to find out the differences in individuals links to self esteem, aggression, and social adjustment. In first study, it involved 94 adolescents who investigated on their friendship jealousy on a newly created measure and they suggested that girls and adolescents with small self-worth observed the greatest friendship jealousy. In the second study 399 young youth were involved and extended the size of self-report jealousy to a broader age range and the results integrated that the self and peer reported jealousy were solitary modestly associated and had different correlates. The structural modeling exposed that young adolescent's status for 


\section{Young Adults and Aggression: A Comparative Study of Gender Differences}

friendship jealousy was connected to behaving aggressively and to broader peer modification difficulties. Both the self and peer observed that jealousy contributed to loneliness. Bailey and Ostrov (2008) conducted a study on aggression in emerging adults. The outcome showed that immediate physical aggression was uniquely connected with hostile acknowledgment biases for instrumental frustration conditions while the reactive relational violence was individually connected with hostile attribution biases for relational provocation scenarios. Their conclusion also showed that there was link between self-reported subtypes of normative beliefs and aggressive behavior. Onukwufor (2013) conducted a study on verbal and physical aggression among adolescents. This study shows significant difference between females and males in respect to physical aggression, suggesting males on higher side.

\section{METHODOLOGY}

\section{Sample}

100 students ( $\mathrm{N}=100$, 50 Males and 50 Females) aging from 19-25 years have been selected randomly from Lovely Professional University (LPU) as a sample in the current study. The mean age of females is 21.72 years and for males 23.16 years.

\section{Research Tool}

Aggression scale: Aggression Scale is developed by Dr. G.P Mathur and Dr Raj Kumari Bhatnagar in 2004. Aggression scale is used to study the level of aggression in any age group (above 14 years). Aggression scale consists of 55 statements. Each statement describes different forms of individual's aggression in different situations. In this scale statements are in two forms i.e. positive and negative. It is a 5 point scale. In this scale the statement are in two forms i.e. positive and negative. 30 statements are in positive forms and 25 in negative form. In positive form of statement, the scores will be given as 5, 4, 3, 2, 1 and in negative form as 1, 2, 3, 4, 5, respectively. The total score will be calculated by adding all the scores of individual items.

\section{Procedure}

First step for this research is to select the subject randomly aging from 19 to 25 inside the LPU campus. After selecting the subject the participate were informed everything about the aggression scale. This scale consists of 55 questions it is a 5 point scale. There is no write and wrong response to the statement. No time limit is fixed for the test but usually an individual takes 25 to 30 minutes to complete this test. But it is compulsory to respond to each question. Finally, the data was computed on suitable statistics including descriptive statistics and test for independent means through SPSS.

\section{RESULTS AND DISCUSSION}

The current study has been performed to investigate the level of aggression and gender differences in aggression among young adults. The results are presented in figure 1, 2 and 3 for males, females and in terms of overall percentage of aggression, respectively. If we carefully analyze the figure 1 and 2, we find that males and females are equal in terms of low aggression as both groups represent 4\% aggression in low category. But, when the high aggression is 


\section{Young Adults and Aggression: A Comparative Study of Gender Differences}

compared, female participants are slightly high and about 30\% female participants show high aggression whereas for male participants the number is $22 \%$. Here we can say that female participants are at $8 \%$ hike on high aggression in comparison to males. The findings are quite surprising as males are generally considered high on aggression than females. The results also show a contrast to the findings of Kenneth E. Leonard (2002) who suggested that $25 \%$ of women and $33 \%$ of men experience aggression. We can say that it is rather opposite in the current study where $30 \%$ female and $22 \%$ male experience high aggression. As the current study is done after 14 years of Kenneth E. Leonard's study, it suggests a changing pattern of aggression in gender perspective.
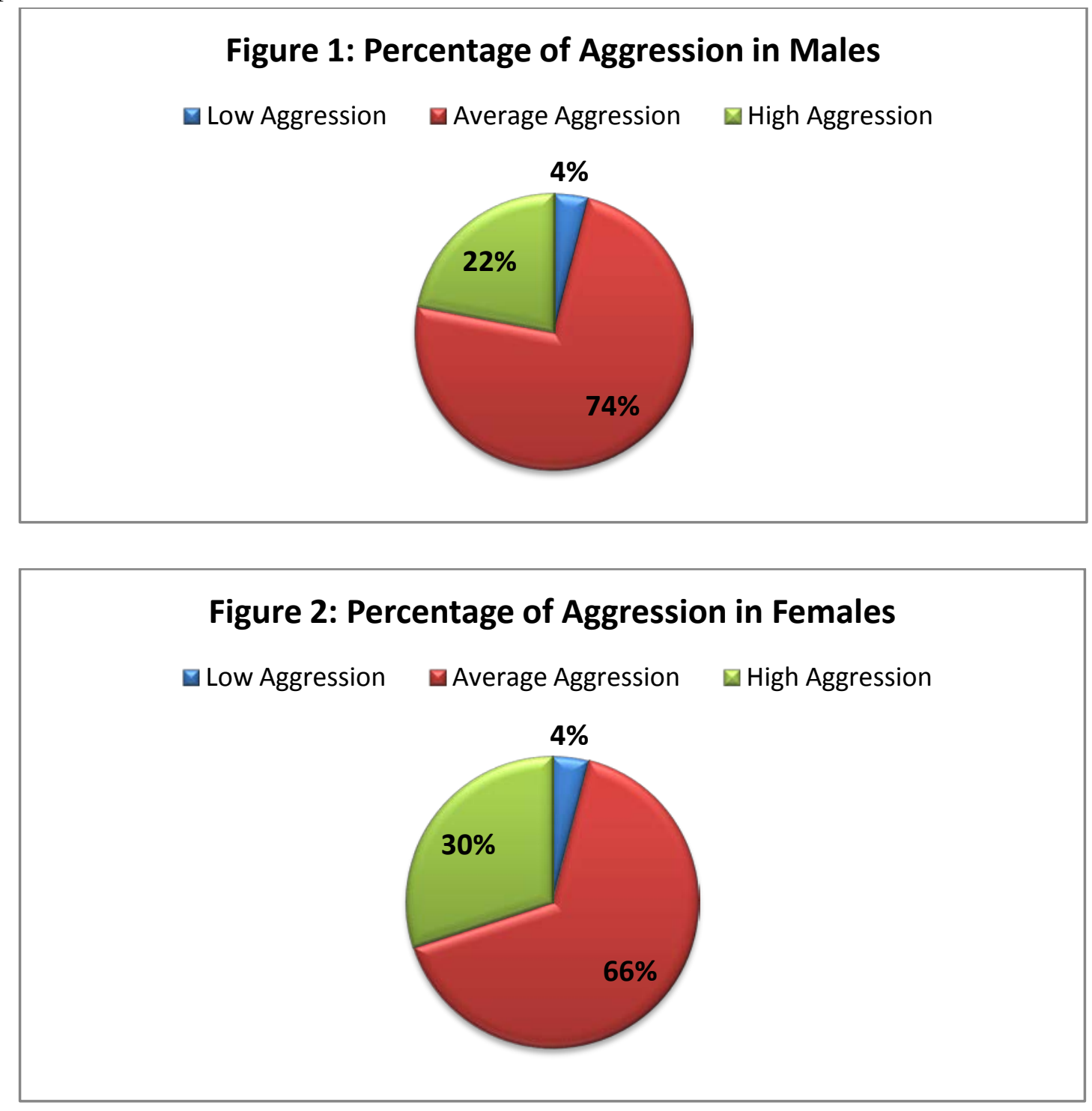

The results also reveal that overall 26\% participants experience high aggression in young adults. This result also suggest that one fourth young adult population fall in the category of high aggression. Figure 3 represents this information graphically. 


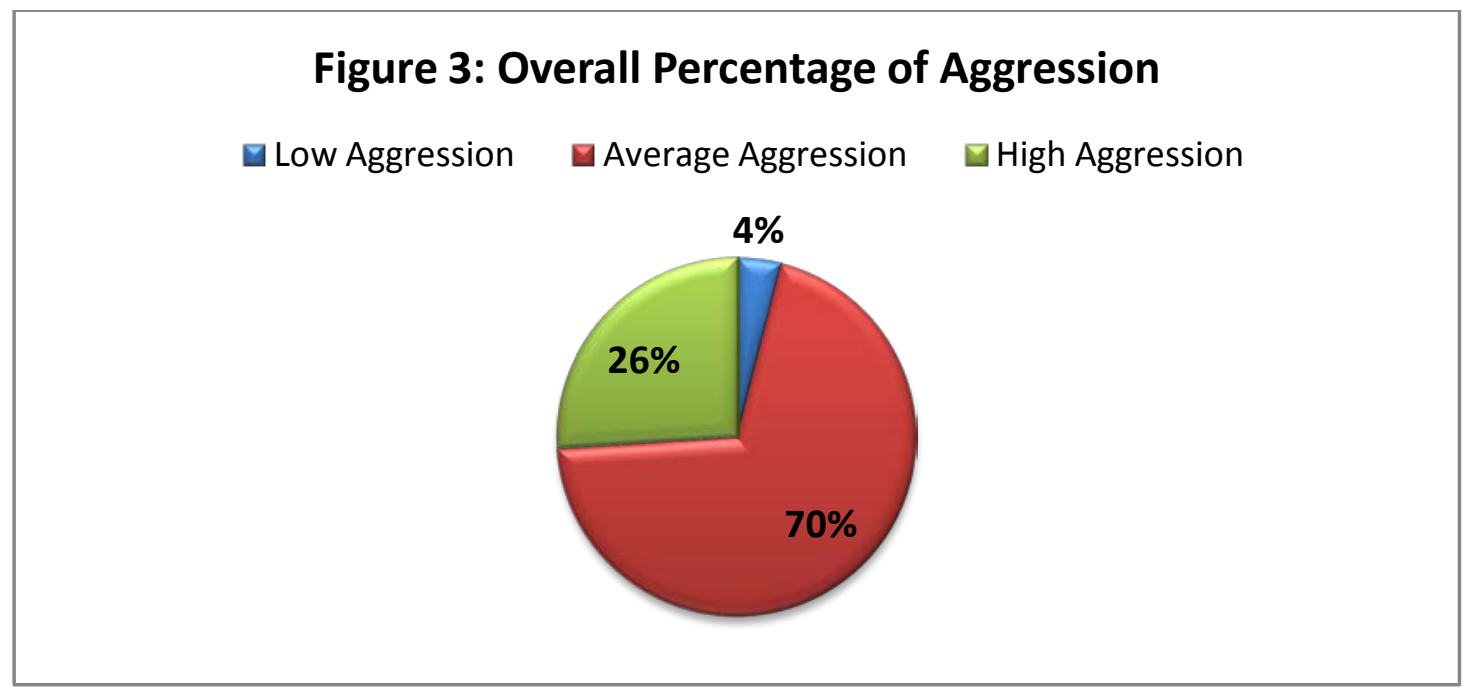

The gender differences in aggression have been calculated by applying independent samples $t$ test (as the data include only two groups) and results are presented in table 1.1. The mean comparison for both the groups is also presented in figure 4 for a visual representation.

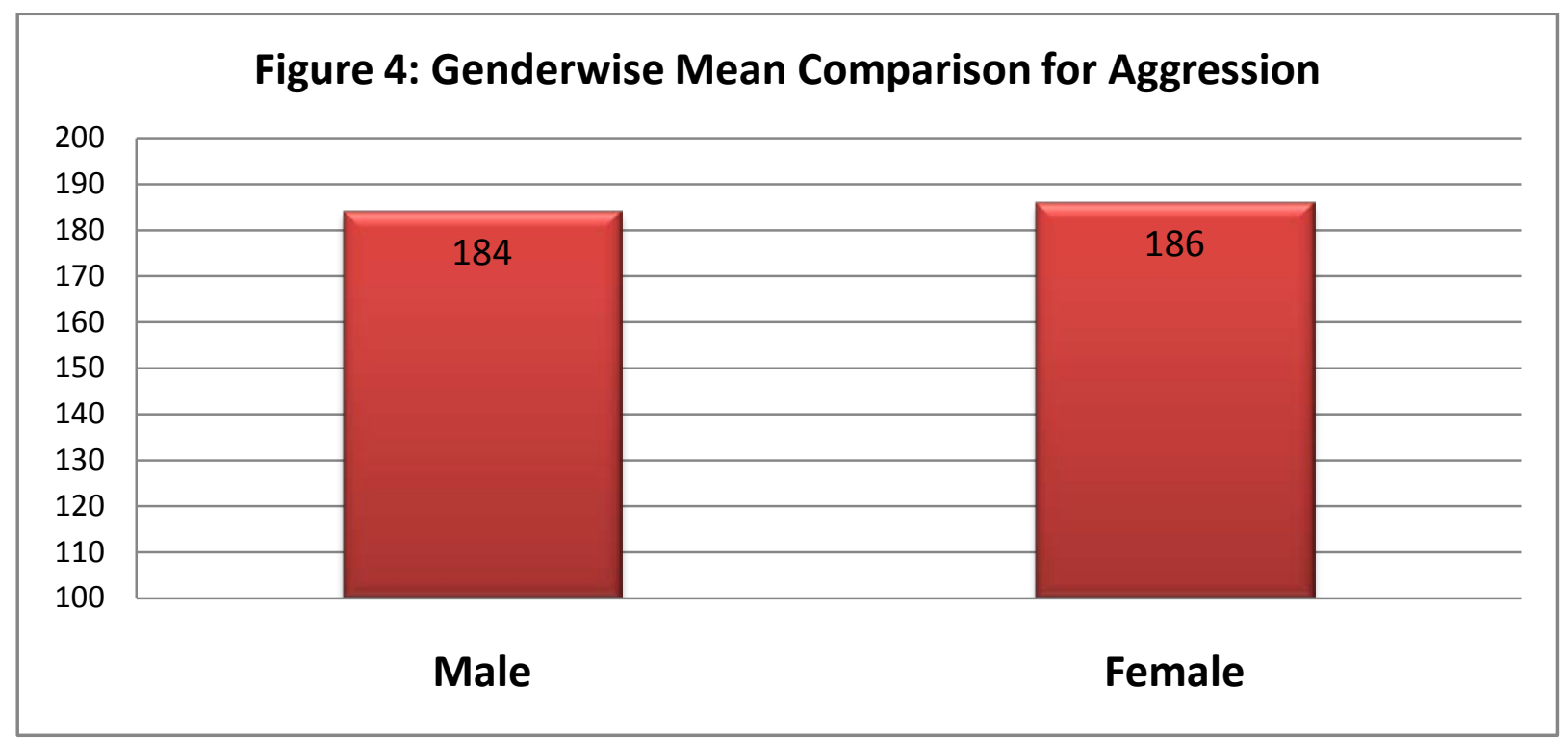

By looking at figure 5, it seems that there no gender difference in aggression. Moreover, when we refer the $t$ ratio for the gender difference $(t=-0.568, p>.05)$ in table 1.1 , we find that the $t$ value is far below from the critical value of probability at .05 level. This also indicates that there is no significant gender difference in aggression. Thus, the results of the current study do not accept the alternate hypothesis that suggests a significant gender difference in aggression. The current results are supported by the findings of Edalati et al. (2010) who suggested that female physical aggression is almost equal to or higher than males but not less than males. The present results are also supported by Smritikana Mitra Ghosh (2012) who did not find any significant difference in aggression between girls and boys in his study. Crick and Grotpeter (1995), Barbara Krahe et al. (2005), Vives and Colet (2010) and Fries et al. (2013) also indicated that females

(C) The International Journal of Indian Psychology, ISSN 2348-5396 (e) | ISSN: 2349-3429 (p) | 112 
were significantly more relationally aggressive or hostile than males. However, we did not find females as significantly higher than males on aggression, but results suggest both are equal on aggression.

Table 1.1: Means, SDs and t ratio for the gender differences in aggression (Independent Samples)

\begin{tabular}{|l|l|l|l|l|l|}
\hline $\mathbf{N}=\mathbf{1 0 0}, \mathbf{d f}=\mathbf{9 8}$ & Gender & Mean & SD & t value & p value \\
\hline \multirow{2}{*}{ Aggression } & Male & 184.26 & 20.66 & & \\
\cline { 2 - 4 } & Female & 186.82 & 24.29 & -0.568 & $0.572(\mathrm{NS})$ \\
\hline NS: Not significant
\end{tabular}

Further, there is a big volume of studies which contrast with the current findings. For example Veiskarami et al. (2015) found in their study that boys average score on aggression was higher than girls. Bettencourt and Miller (1996) also found out a contrast to the current study suggesting that the men who are unprovoked are more aggressive as compare to women. Similarly, the study by Jamal Akhtar et al. (2015) does not support the current research findings revealing that the girls are relatively less aggressive as compared to boys.

\section{CONCLUSION}

In nutshell, we can say that there is no consensus over gender differences on aggression but researches are scattered in view of suggesting males as high, equal or low to females on aggression. However, most of the current researches suggest that there is no significant gender difference on aggression. The current research also supports the view and indicates that both males and females are equal on experiencing aggression. Though, the present research uses a small sample, which becomes its limitation, yet it gives new insights to future researchers interested to conduct researches in areas related to aggression.

\section{Acknowledgments}

The author appreciates all those who participated in the study and helped to facilitate the research process.

\section{Conflict of Interests}

The author declared no conflict of interests.

\section{REFERENCES}

Akhtar, J., \& Kushwaha, A. K. S., (2015). Gender differences in aggressive behavior of adolescents. Research paper, 5. 525-527

Bailey, C. A., \& Ostrov, J. M., (2008). Differentiating forms and functions of aggression in emerging adults: associations with hostile attribution biases and normative beliefs, $J$ Youth Adolescence, 37:713-722 


\section{Young Adults and Aggression: A Comparative Study of Gender Differences}

Baron, R. A., \& Richardson, D. R. (1994). Human aggression ( ${ }^{\text {nd }}$ ed.). New York: plenum

Bettencourt, B. H., \& Miller, N., (1996). Gender differences in aggression as a function of provocation: A meta- analysis, Psychological Bulletin, 119, 422-447

Bjorkquist, K., Osterman, K., \& Lagerspetz, M, J., (1994). Sex differences in covert aggression among adults, aggressive behavior, 20, 27-33

Buss, A. H. (1961).The Psychology of Aggression. New York: Wiley.

Crick, N. R., \& Grotpeter, J. K. (1995). Relational aggression, gender, and social-psychological adjustment. Child Development, 66, 710-722.

Crick, N. R., \& Grotpeter, J. K., (1995). Rational aggression, gender and social psychological adjustment, Society for research in child development, 66, 710-722

Eagly, A. H., \& Steffen, V. J. (1986). Gender and aggressive behavior. A meta-analytic review of the social psychological literature. Psychological Bullentin, 100, 309-330.doi: 10.1037/0033-2909.100.3.309

Edalati, A., \& Redzuan, M., (2010) women aggression (A Review). Report and opinion, 2

Estevez, E., Povedano. A., Jimenez. T. I., \& Musitu. G., (2012) Aggression in adolescence: A gender prespective, psychology of aggression: new research, pp 37- 57

Fares, N. E., Ramirez, J. H., Cabrera, J. M., Lozano, F., \& Sales, F (2011). Justification of physical and verbal aggression in Uruguayan children and adolescents, The open journal, 4, 45-54

Fries, L., Kaylor, G. A., Bares, C., Han, Y., \& Delva, J., (2013). Gender differences in predictors of self- reported physical aggression: Exploring theoretically relevant dimensions among adolescents from Santigo, Chile, 2

Ghosh, S. M., (2013). A comparative study on aggression between boys and girls adolescent. International journal of behavioral social and movement sciences, 2, 76-82

Hay, D., (2007). The gradual emergence of sex differences in aggression alternative hypothesis, Psychological medicine, pp 1 of 11, doi:10.1017/S00332917070001

Krahe, B., \& Berger, A., (2005). Sex difference in aggression among young adults in Germany. Sex Roles, 52, 829-838

Onukwufor, J. N., (2013). Physical and verbal aggression among adolescent secondary school students in rivers state of Nigeria, British Journal of Education, 2, 62-73

Parker, J. G., Low, C. M., Walker, A. R., \& Gamm, B .K., (2005). Friendship Jealousy in Young Adolescents: Individual Differences and Links to Sex, Self-Esteem, Aggression, and Social Adjustment, Developmental Psychology, 41, 235-250

Veiskarami, H., A., Salimy, H., Zangiabad, M., \& Hosseini, S.A., (2015). Comparative analysis of physical victimization among male and female high school students of Iran. International journal of science, 9, 9-12

Vives, F.M., Colet, A.V., (2010). Are there sex differences in physical aggression in the elderly, Personality and Individual Differences, 49 ,659-662

How to cite this article: N Shaban, P Kumar (2016), Young Adults and Aggression: A Comparative Study of Gender Differences, International Journal of Indian Psychology, Volume 3, Issue 4, No. 57, ISSN 2348-5396 (e), ISSN: 2349-3429 (p), DIP: 18.01.031/20160304, ISBN: 978-1-365-23993-9 